\title{
RESPONSES OF TWO LEAFROLLER SPECIES TO THE PHOTOACTIVE DYE PHLOXINE B
}

\author{
M.R. McNEILL and S.L. GOLDSON \\ AgResearch, Biocontrol and Biosecurity Group, PO Box 60, Lincoln, \\ Canterbury, New Zealand \\ Corresponding author: mark.mcneill@agresearch.co.nz
}

\begin{abstract}
The insecticidal properties of phloxine B were evaluated against lightbrown apple moth (LBAM) Epiphyas postvittana and green headed leafroller (GHLR) Planotortix excessana in laboratory bioassays. A range of concentrations of phloxine B were added to general purpose diet and presented to larvae in Petri dishes. High rates of mortality (80-94\%) were achieved at concentrations of $0.2-1.0 \%$ phloxine $\mathrm{B}$, with $\mathrm{LC}_{50}$ values of ca $0.1 \%$ and $0.27 \%$ for $1^{\text {st }}$ instar LBAM and GHLR, respectively. The susceptibility of leafroller larvae to phloxine B was affected by light intensity and instar.
\end{abstract}

Keywords: Epiphyas postvittana, Planotortix excessana, leafroller, phloxine B, xanthene dyes, photoactive dyes.

\section{INTRODUCTION}

Phloxine B is a photoactive dye belonging to a series of halogenated xanthene dyes, and is registered with the US Food and Drug Administration as an approved colorant D\&C red dye \#28 in drugs and cosmetics (Lipman 1995). It has very low toxicity to mammals with an acute oral $\mathrm{LD}_{50}$ of $8400 \mathrm{mg} / \mathrm{kg}$ to male rats (Bergsten 1995). By contrast, research over the last 30 years in the USA has shown phloxine B to be active against at least 24 insect pests, including fire ants (Solenopsis spp.) (David \& Heitz 1978), corn rootworm (Diabrotica spp.) (Schroder et al. 1998), and Mexican fruit fly Anastrepha ludens (Moreno \& Mangan 1995). Phloxine B is highly specific to targeted pests, as it needs to be ingested to exert a toxic effect.

The mechanism for photodynamic activity has been described by Heitz (1995). Toxicity occurs at the cellular level with the dye acting as a catalyst for the generation of singlet oxygen molecules. This leads to the initiation of oxidation reactions that destroy several target molecules in the cell. No products using phloxine B as the active ingredient are currently registered for use against insects, although an application was lodged with the US EPA for a phloxine B-bait combination (SureDye ${ }^{\mathrm{TM}}$ ) to control adult Mediterranean fruit fly (Tephritidae) (Heitz 1998).

This contribution reports on laboratory experiments to investigate the activity of phloxine B using two New Zealand tortricid pests, lightbrown apple moth (LBAM) Epiphyas postvittana (Walker) and green headed leafroller (GHLR) Planotortix excessana (Walker).

\section{MATERIALS AND METHODS}

Ingestion of phloxine $B$

First or $2^{\text {nd }}$ instar LBAM and GHLR larvae and general purpose diet (GPD) were obtained from HortResearch, Auckland. Phloxine B was supplied by Warner Jenkinson Co., Inc. USA. Differing dye concentrations were mixed into $20 \mathrm{~g}$ of GPD with $1 \%$ adjuvant (Tween 20). Aduvants have been shown to enhance the toxicity of phloxine B (Heitz et al. 1997). The phloxine B-GPD mixture was cut into $10 \mathrm{~mm}$ circular or square plugs and placed individually in the middle of $60 \mathrm{~mm}$ diameter x $15 \mathrm{~mm}$ deep Petri 
dishes. The control was GPD plus $1 \%$ adjuvant. Indentations were made into the surface of the diet to provide sites in which the larvae could settle and feed. Plugs were air dried for 45-60 min in a laminar flow cabinet to reduce the mixture's moisture content and prevent larvae from drowning.

Neonate larvae were between 36-96 h old prior to placement on the diet with a moistened camel hair paint brush (No 0). The Petri dishes were then placed in a dark controlled environment chamber (Contherm) at $20^{\circ} \mathrm{C}$ for $45-180 \mathrm{~min}$ to allow the larvae to establish on the plugs. Larvae were able to feed ad libitum and move off the diet. Feeding by larvae was readily discerned since their gut turned red as a result of dye ingestion. Dishes were checked prior to commencement of the bioassay to ensure that the larvae were alive.

\section{Environment}

The bioassays were carried out in a controlled environment room at the AgResearch insect rearing facility at Lincoln. The shelves on which the experiments were carried out were next to a Polygal ${ }^{\mathrm{TM}}$ window that supplied a diffuse natural light. This provided the low intensity light treatment. For the high intensity light treatment (lights) additional lighting was provided from two overhead Phillips TLD $58 \mathrm{~W}$ Cool Daylight fluorescent tubes, with a spectral distribution of 400-700 and peaks at ca 420, 550 and $620 \mathrm{~nm}$. Maximum absorbance of phloxine B occurs at the $540 \mathrm{~nm}$ wavelength. The Petri dishes were ca $32 \mathrm{~cm}$ below the fluorescent tubes. To minimise transfer of heat from the shelf surface, Petri dishes were placed on a white plastic grill.

The photoperiod was 11:13 h light:dark, going on at $0730 \mathrm{hrs}$ and off at 1830 hours. Temperature was monitored using Tinytag ${ }^{\mathrm{TM}}$ loggers. Light intensity was measured using a digital lux meter, which provided an estimate of the energy per unit area falling on a surface. Treatments were laid out in a completely randomised design.

Experiment 1: Responses of $1^{\text {st }}$ and $2^{\text {nd }}$ instar LBAM to phloxine $B$

First and second instar LBAM were placed on the GPD containing different concentrations of phloxine B and kept in the dark for $180 \mathrm{~min}$. They were then placed under the lights at 1500 hours and mortality determined after 24 hours. Phloxine B concentrations were 0 (control), $0.01,0.05,0.1,0.2,0.5$ and $1 \%$. There were five replicates per treatment.

\section{Experiment 2: Responses of $1^{\text {st }}$ instar LBAM and GHLR to phloxine B}

First instar LBAM and GHLR were placed on the phloxine B-GPD mixture and then placed into the dark for ca 60 min before being placed under lights at 1300 hours. Phloxine B concentrations tested were 0 (control), $0.01,0.05,0.1,0.2,0.5,1$ and $5 \%$ with six replicates per treatment. Mortality was assessed 2 and $31 \mathrm{~h}$ after placement under lights. Experiment 3: Interaction of leafroller species, light intensity and exposure duration on mortality.

First instar larvae LBAM and GHLR were placed on the phloxine B-GPD mixture and held in the dark for ca $30 \mathrm{~min}$. Larvae were placed either on the shelf receiving only natural light or beneath the lights. Phloxine B concentrations were 0 (control), 0.1 and $0.5 \%$ with five replicates per treatment. Mortality was assessed 6,24 and $30 \mathrm{~h}$ after placement on the shelves at 1000 hours.

\section{Data analysis}

For analysis, the total number of larvae exposed and number dying at each concentration were pooled across replicates. The $\mathrm{LC}_{50}$ values for experiments 1 and 2 were estimated using PROBIT analysis. The goodness of fit for the regression for $\mathrm{LC}_{50}$ was assessed by $\chi^{2}$ method, with $\mathrm{n}-\mathrm{p}(\mathrm{n}=$ number of concentrations and $\mathrm{p}=$ number of parameters $)$ degrees of freedom. For experiment 3 , the effect of light intensity, leafroller species and phloxine $\mathrm{B}$ concentration and their interactions were analysed using the Generalised Linear Model (GLIM) procedure (McCullagh \& Nelder 1983). Mortality data presented in the text were corrected for control mortality using Abbot's formula (Abbott 1925). All analyses were carried out using Genstat. 
Experiment 1

\section{RESULTS}

Mortality of $1^{\text {st }}$ instar larvae increased with increasing dye concentration between 0.01 to $0.2 \%$ phloxine B. Mortality at 0.2 and $0.5 \%$ was similar (ca $79 \%$ ) but at $1.0 \%$ phloxine B, $1^{\text {st }}$ instar mortality was $93 \%$ (Fig. 1). Mortality of $2^{\text {nd }}$ instar larvae was more variable over the range of concentrations tested (Fig. 1), with $0.1,0.2$ and $0.5 \%$ phloxine $\mathrm{B}$ producing similar levels of mortality of ca $51 \%$. Eighty-five percent of $2^{\text {nd }}$ instar larvae died after feeding on $1.0 \%$ phloxine $\mathrm{B}$ for 24 hours. The $\mathrm{LC}_{50}$ for $1^{\text {st }}$ and $2^{\text {nd }}$ instar larvae was 0.09 and $0.2 \%$ respectively (Table 1$)$. There were significant differences between the respective mean $\mathrm{LC}_{50}$ values $\left(\chi^{2}=5.5, \mathrm{df}=1, \mathrm{P}<0.05\right)$ and slopes $\left(\chi^{2}=5.0\right.$, $\mathrm{df}=1, \mathrm{P}<0.05)$ of the dose-response curves for the two instars.

TABLE 1: Response of $1^{\text {st }}$ and $2^{\text {nd }}$ instar LBAM exposed for 24 hours (Experiment 1) and $1^{\text {st }}$ instar LBAM and GHLR exposed for 31 hours (Experiment 2) under fluorescent lights to different concentrations of phloxine $B$.

\begin{tabular}{lccccccc}
\hline & $\begin{array}{c}\text { Total } \\
\text { number }\end{array}$ & $\mathrm{LC}_{50}(\%)$ & $95 \%$ C.I. & Slope & $\mathrm{SE}$ & $\chi^{2}$ & df \\
\hline Experiment 1 & & & & & & & \\
LBAM 1 $^{\text {st }}$ instar & 197 & 0.09 & $0.07-0.14$ & 0.675 & 0.10 & 0.771 & 5 \\
LBAM 2 $^{\text {nd }}$ instar & 138 & 0.21 & $0.08-0.52$ & 0.412 & 0.12 & 0.286 & 5 \\
Experiment 2 $_{\text {LBAM 1 }}^{\text {st } \text { instar }}$ & 333 & 0.10 & $0.06-0.17$ & 0.53 & 0.08 & 0.062 & 5 \\
GHLR 1 $^{\text {st }}$ instar & 262 & 0.27 & $0.15-0.48$ & 0.51 & 0.09 & 0.003 & 6 \\
\hline
\end{tabular}

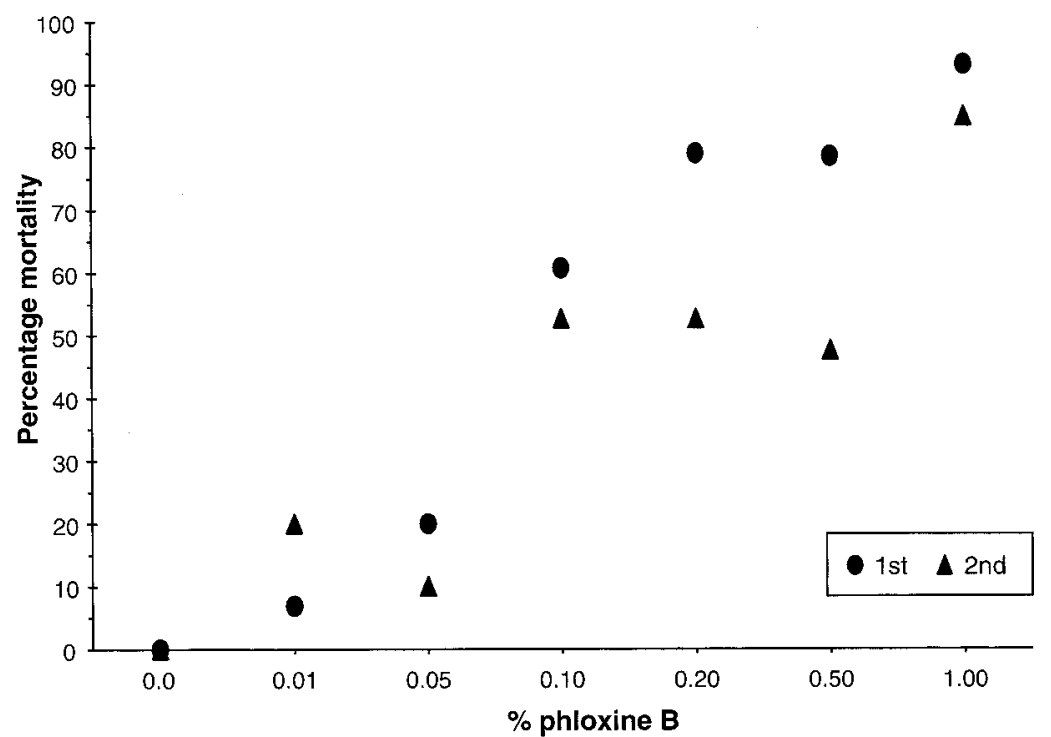

FIGURE 1: Comparative mortality of LBAM $1^{\text {st }}$ and $2^{\text {nd }}$ instar larvae $24 \mathrm{~h}$ after feeding on varying concentrations of phloxine $B$ and exposure to fluorescent lights. 


\section{Experiment 2}

After $2 \mathrm{~h}$ under lights, mortality of LBAM larvae between phloxine B concentrations of 0.01 and $0.2 \%$ was negligible. Mortality of larvae feeding on $0.5,1$ and $5 \%$ phloxine B was $15.2,13.4$ and $55.5 \%$ respectively. GHLR mortality only occurred at rates above $0.2 \%$, with 9,16 and $11 \%$ of larvae dead at $0.5,1$ and $5 \%$ phloxine B respectively. There were significant species $\left(\chi^{2}=7.5, \mathrm{df}=1, \mathrm{P}=0.006\right)$ and rate $\left(\chi^{2}=14.1, \mathrm{df}=7, \mathrm{P}<001\right)$ effects.

After $31 \mathrm{~h}$, increased mortality of LBAM larvae was associated with increasing concentration with the greatest mortality (94\%) occurring at $1 \%$ phloxine B (Fig 2). Mortality of GHLR generally increased with increasing concentration with $89 \%$ of larvae dying at $5 \%$ phloxine $\mathrm{B}$. After $31 \mathrm{~h}$ exposure to the dye, the $\mathrm{LC}_{50}$ for $\mathrm{LBAM}$ was $0.10 \%$ (assessed from concentrations $0.01-1 \%$ phloxine B) and for GHLR was $0.27 \%$ (Table 1). The $\mathrm{LC}_{50}$ means for the two species were significantly different $\left(\chi^{2}=14, \mathrm{df}=1\right.$, $\mathrm{P}<0.001)$ but the slopes were not $\left(\chi^{2}=0.05, \mathrm{df}=1, \mathrm{P}>0.05\right)$. During the bioassay the temperature averaged $17.1^{\circ} \mathrm{C}$ (range $21.2-24.7^{\circ} \mathrm{C}$ ) with light intensity averaging 10753 (range 8760-12 900) lux when lights were on.

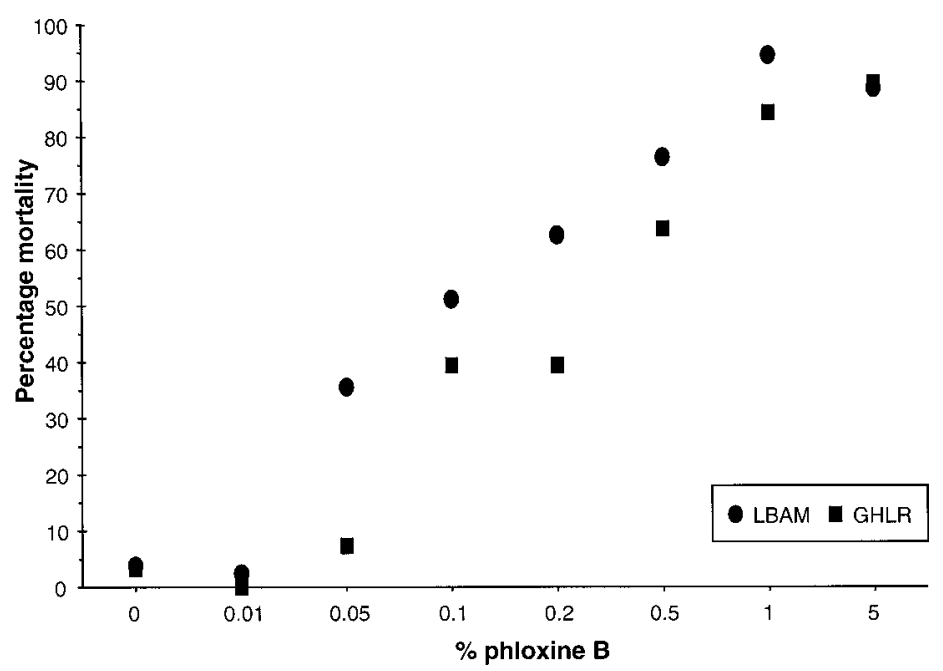

FIGURE 2: Comparative mortality of $1^{\text {st }}$ instar LBAM and GHLR 31 h after feeding on varying concentrations of phloxine $B$ and exposed to fluorescent lights.

\section{Experiment 3}

The results of the 6 and $24 \mathrm{~h}$ exposure to phloxine B are not presented, but showed higher mortality of LBAM than GHLR for all treatments, higher mortality under lights and increasing mortality with duration of exposure to phloxine B. Overall, for both leafroller species there was a significant phloxine $\mathrm{B}$ concentration $\left(\mathrm{F}_{2,14}=86.8, \mathrm{P}<0.001\right)$ and exposure-duration $\left(\mathrm{F}_{2,14}=46.4, \mathrm{P}<0.001\right)$ effect on mortality. Analysis of the $30 \mathrm{~h}$ results (Table 2 ), showed that overall mortality of LBAM was slightly higher than GHLR but the difference was not significant $\left(\chi^{2}=1.5, \mathrm{df}=1, \mathrm{P}=0.35\right)$. There were significant concentration $\left(\chi^{2}=303.0, \mathrm{df}=2, \mathrm{P}=0.003\right)$ and light intensity $\left(\chi^{2}=114.9, \mathrm{df}=1, \mathrm{P}=0.009\right)$ effects. There was also a significant leafroller species $\mathrm{x}$ concentration interaction $\left(\chi^{2}=\right.$ $33.8, \mathrm{df}=2, \mathrm{P}=0.03$ ), but all other interactions were not significant. 
TABLE 2: Mortality ( $\%$ ) of $1^{\text {st }}$ instar LBAM and GHLR exposed to 0.1 and $0.5 \%$ phloxine $B$ after 30 hours under low and high light intensities. Results corrected for control mortality using Abbott's formula.

\begin{tabular}{lccc}
\hline \multirow{2}{*}{ Leafroller species } & Phloxine B $(\%)$ & \%ow light & High light \\
\cline { 3 - 4 } LBAM & 0.1 & $36(28)$ & $56(25)$ \\
GHLR & 0.5 & $50(26)$ & $85(27)$ \\
& 0.1 & $9(25)$ & $37(27)$ \\
& 0.5 & $37(24)$ & $76(23)$ \\
\hline
\end{tabular}

The light intensity measured under the two fluorescent tubes averaged 11065 (range 10 283-12 963) lux, compared with 2323 (1407-3810) lux for insects receiving only natural light through the Polygal ${ }^{\mathrm{TM}}$ windows. Mean temperatures for both treatments were similar $\left(\mathrm{ca} 16.8^{\circ} \mathrm{C}\right.$ ) although the temperature range measured under high light intensity $\left(22.2-26.3^{\circ} \mathrm{C}\right)$ was slightly higher than under low light intensity $\left(21-24.2^{\circ} \mathrm{C}\right)$.

\section{DISCUSSION}

Phloxine B was shown to have activity against the two leafroller species tested. Second instar LBAM were 2.3-fold more tolerant to phloxine B than $1^{\text {st }}$ instar LBAM. The higher tolerance of $2^{\text {nd }}$ versus $1^{\text {st }}$ instar larvae is to be expected, given their greater mass and darker body pigmentation which light had to penetrate to effect photodynamic activity. The level of mortality generally increased with concentration although in Experiment 1, mortality among $2^{\text {nd }}$ instar LBAM was variable, with mortality comparable for $0.1,0.2$ and $0.5 \%$ phloxine B. This may simply reflect differences in consumption of the dye with a consequent effect on mortality. Failure to feed due to pre-ecdysis gut changes may also have been a factor in this result (D. Johnson, pers. comm.). First instar LBAM was significantly more susceptible than $1^{\text {st }}$ instar GHLR to phloxine B, with significantly higher mortality occurring after $2 \mathrm{~h}$ of exposure to lights. Overall, LBAM was 2.7-fold more susceptible than GHLR to phloxine B. Light intensity was shown to have a significant effect on mortality for both leafroller species. Perhaps not surprisingly, the duration of exposure also lead to increased mortality.

The light intensities used in these experiments were generally less than those measured outdoors. The light intensity in full daylight with indirect sunlight is 10 000-20 000 lux and greater than 100000 lux for direct sunlight. This may have had a significant impact on reducing the time taken to kill target species. For example, Schroder et al. (1998) found $90 \%$ of corn rootworm adults died after $1 \mathrm{~h}$ in full sunlight compared with $48 \mathrm{~h}$ under fluorescent lights.

Overall, the results show that phloxine B was effective in killing early instar LBAM and GHLR when incorporated in an artificial diet. Sophisticated baits have been developed for corn rootworm (Schroder et al. 1998) and fruitfly (Moreno \& Mangan 1995), that incorporate dye, feeding stimulants and various adjuvants to attract the target pest and induce feeding. Similar refinements for a leafroller-specific bait may also be possible. On a wider scale, because phloxine $B$ has negligible human and environmental effects (Bergsten 1995; Heitz 1998), it would appear to be very suitable for use as a pest-specific insecticide in urban or ecologically sensitive environments.

\section{ACKNOWLEDGEMENTS}

The authors thank David Baird for statistical advice and analysis, and Colin Ferguson, Bruce Chapman and James Heitz for comments on the original manuscript. 


\section{REFERENCES}

Abbott, W.S. 1925: A method of computing the effectiveness of an insecticide. J. Econ. Ent. 18: 265-267.

Bergsten, D.A. 1995: Risk assessment: Phloxine B and Uranine insecticide application trials. In: Heitz, J.R.; Downum, K.R. ed. Light-activated pest control. ACS Symposium Series 616. American Chemical Society, Washington, DC, USA. Pp. 54-69.

David, R.M.; Heitz, J.R. 1978: Toxicity of an imported fire ant bait based on Phloxin B (D+C Red 27). J. Agric. Food Chem. 26: 99-101.

Heitz, J.R. 1995: Pesticidal applications of photoactivated molecules. In: Heitz, J.R.; Downum, K.R. ed. Light-activated pest control. ACS Symposium Series 616. American Chemical Society, Washington, DC, USA. Pp. 1-16.

Heitz, J.R. 1998: Reduced Risk Rationale for phloxine B - formulated as SureDye ${ }^{\mathrm{TM}}$ bait. Unpublished report to US Environmental Protection Agency. $81 \mathrm{p}$.

Heitz, J.R.; Mangan, R.L.; Moreno, D.S. 1997: Phototoxic insecticidal composition and method for controlling insect populations. U.S. Patent 5,676,959. $10 \mathrm{p}$.

Lipman, A.L. 1995: Safety of Xanthene dyes according to the U.S. Food and Drug administration. In: Heitz, J.R.; Downum, K.R. ed. Light-activated pest control. ACS Symposium Series 616. American Chemical Society, Washington, DC, USA. Pp. 34-53

McCullagh, P.; Nelder, J.A. 1983: Generalized linear models. London: Chapman \& Hall, $261 \mathrm{p}$.

Moreno, D.S.; Mangan, R.L. 1995: Responses of the Mexican fruit fly (Diptera: Tephritideae) to two hydrolyzed proteins and incorporation of Phloxine B to kill adults. In: Heitz, J.R.; Downum, K.R. ed. Light-activated pest control. ACS Symposium Series 616. American Chemical Society, Washington, DC, USA. Pp. 257-279.

Schroder, R.F.W.; DeMilo, A.B.; Lee-Chang Joo; Martin, P.A.W; Lee, C.J. 1998: Evaluation of a water-soluble bait for corn rootworm (Coleoptera: Chrysomelidae) control. J. Entomol. Sci. 33: 355-364. 